\title{
VALIDATION OF MODIS MCD45A1 PRODUCT TO IDENTIFY BURNED AREAS IN ACRE STATE - AMAZON FOREST
}

\author{
Francielle da Silva Cardozo ${ }^{I}$, Gabriel Pereira ${ }^{l}$, Yosio Edemir Shimabukuro ${ }^{l}$, Elisabete Caria Moraes ${ }^{l}$ \\ National Institute for Space Research (INPE) ${ }^{1}$
}

\begin{abstract}
Burned areas map is essential in many applications and the orbital sensors have been used to monitor fires for many years, providing a better understanding of processes at different scales and being the only practical technique to estimate fires in large areas. However, remote sensing methods have limitations that could cause errors in the final products. Therefore, the objective of this work is to evaluate the MCD45A1 burned area product derived from MODIS sensor in Amazon tropical forest by comparing this dataset with the reference data derived from the mapping of burned areas in Acre State/Brazil acquired by TM sensor aboard of Landsat 5 and with a fieldwork that took place in November 2011. The results showed that de MCD45A1 product presented $93 \%$ of omission errors in 2010 and $96 \%$ in 2011 year in relation to reference data, presenting a low confidence in identifying the burned areas in Amazon region.
\end{abstract}

Index Terms - Environmental factors, remote sensing, remote monitoring, vegetation mapping

\section{INTRODUCTION}

The burning areas represent one of the most important mechanisms of changes in land cover and are used mainly in the practice of grass renewal and deforestation, and every year, fire affects millions of hectares of forests around the world, causing several impacts, mainly due to changes in biophysical parameters associated with land cover, causing serious modifications in the biosphere-atmosphere components [1]. In Brazil, especially in the Amazon region, fires are caused by human activity related to the expansion of agriculture, deforestation, pasture renewals and pest control [2].

The identification and understanding of fires behavior are essential to prevent and to mitigate the impacts in environmental variables, and the estimate and the delimitation of the burned area is a key factor for this purpose [3]. Burned areas map is essential in many applications, especially in the estimation of the trace gases and aerosols emissions into the atmosphere [4]. Also, the recognition of biomass burning as an important modifying agent of the earth's surface contributed with the necessity of information of better spatial and temporal scales, obtained partially by data derived from orbital sensors that detect active fires and the total burned area, such as the MOD14A2/MYD14A2 and MCD45A1 products of Moderate Resolution Imaging Spectroradiometer (MODIS) sensor [5].

The orbital sensors have been used to monitor and detect fires for many years, providing a better understanding of processes at different scales and being the only practical technique to estimate fires in large areas, especially due to synoptic view characteristics, high efficiency of new information over the same area and low cost [3]. However, remote sensing methods have limitations that could cause errors in the final products [6]. Some studies using nonautomatic methods to map burned scars derived from satellites with better spatial resolution, such as Landsat 5, were performed to validate the automatic products of burned area [7].

Therefore, the objective of this work is to evaluate the MCD45A1 burned area product derived from MODIS sensor in Amazon tropical forest by comparing this dataset with the reference data derived from the mapping of burned areas in Acre State/Brazil acquired by Thematic Mapper (TM) sensor aboard of Landsat 5 satellite and with a fieldwork that took place in November 2011.

\section{MATERIALS AND METHODS}

The study area is composed by the Acre State, located in the Brazilian Amazon tropical forest, as shown in Figure 1. In this work, to evaluate the MCD45A1 product, we used 32 TM/Landsat 5 cloud free imagery for 2010 year and 24 images for 2011 year. In this work, the images were geometrically corrected using manually selected control points to fit and apply a first order polynomial and a nearest neighbor resampling. The resulting root mean square error was less than 0.5 pixels. 


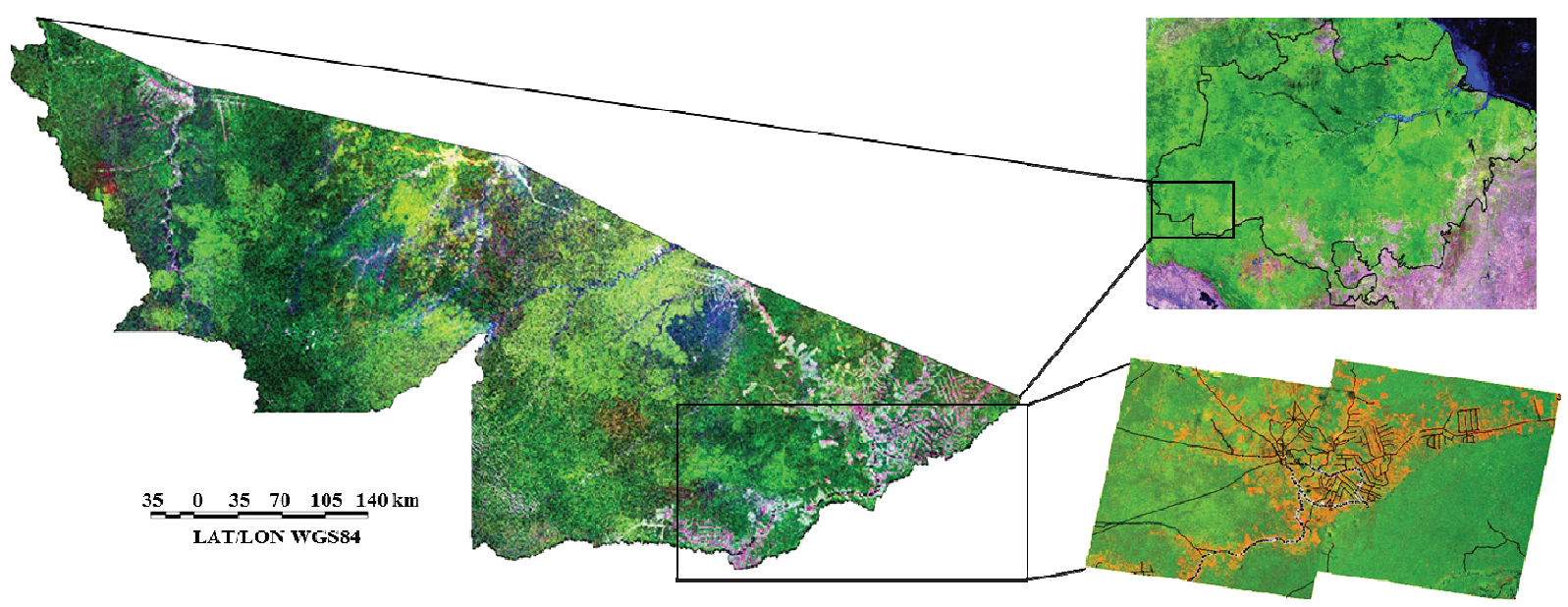

Figure 1. Study area location with points collected in fieldwork.

The georeferenced images were inserted in Georeferenced Information Processing System (SPRING), a geographic information system developed by the National Institute for Space Research (INPE), to separate the regions of a segmented image with a similarity of eight and a minimal area of 12 pixels. As a result, the burned area was manually mapped through image segmentation and subsequent manual edition of polygons to avoid errors. As the automatic classification procedures can often confuse similar spectral patterns, as shown by fire scars and other elements contained in the images, such as water bodies, cloud shadows or terrain accidents, the use of visual interpretation was considered the most appropriate. The two periods of analysis were chosen in order to compare the evolution of the burned areas and due to the fieldwork realized in 2011.

The product evaluated was the MCD45A1 of MODIS aboard Terra and Aqua platforms, which represent the burned areas, obtained daily, with spatial resolution of 500 meters, composed by a monthly mosaic, relative to 12 datasets for the 2010 and 2011 years. The evaluation of MCD45A1 product was performed by analysis and comparison with TM/Landsat 5 images and with a fieldwork that took place in Rio Branco - Acre in November 2011.

The pre-processing of MCD45A1 was performed through the conversion of data, in Hierarchical Data Format (HDF) to geotiff, in MODIS Reprojection Tool (MRT). After the stage of pre-processing, the images were inserted into SPRING. As the spatial resolution of the TM/Landsat 5 sensor is 30 meters, we interpolate the MCD45A1 product to the same spatial resolution, facilitating the analysis and comparison that was performed by cross tabulation in SPRING.

\section{RESULTS AND DISCUSSIONS}

Figure 2a and 2c shows the mapped burned areas for 2010 and 2011 year respectively in Acre state using multitemporal TM images (used in this work as reference due to better spatial resolution), and Figure $2 \mathrm{~b}$ and $2 \mathrm{~d}$ represents the burned areas obtained from the product MCD45A1.

In Figure 2a, the mapped burned area originated from reference images was $2,123 \mathrm{~km}^{2}$, while MCD45A1 product estimated the burned area in $157 \mathrm{~km}^{2}$ (Figure 2b). Comparing the two results, derived from cross tabulation and considering the surrounding areas with pixels of $2 \mathrm{~km}$, they agree in $7 \%$ of total map area $\left(155 \mathrm{~km}^{2}\right)$. However, errors of commission represented $1 \%$ of the total area estimated by MDC45A1, or $2 \mathrm{~km}^{2}$. Moreover, the MCD45A1 missed $1,966 \mathrm{~km}^{2}$ of burned areas, equivalent to $93 \%$ of omission in relation to reference data.

According to Figure 2c, we find that the occurrence of fires has decreased considerably in 2011 year, presenting $469 \mathrm{~km}^{2}$ of total burned areas in reference images, and among the factors responsible for this decrease, we can mention the higher volume of precipitation for the year 2011 compared to 2010 and especially because of the implementation of public policies by the Acre State, such as the increase of inspection, the certification of properties and the use of alternative techniques to the use of fire.

Related to the MCD45A1 product, the burned areas estimated was only $19 \mathrm{~km}^{2}$, representing $11 \%$ of commission $\left(2 \mathrm{~km}^{2}\right), 96 \%$ of omission $\left(452 \mathrm{~km}^{2}\right)$ and only $4 \%$ of agreement $\left(17 \mathrm{~km}^{2}\right)$, and can be noted that when the pixels of burned area are very small, the identification by MODIS becomes more failure. 


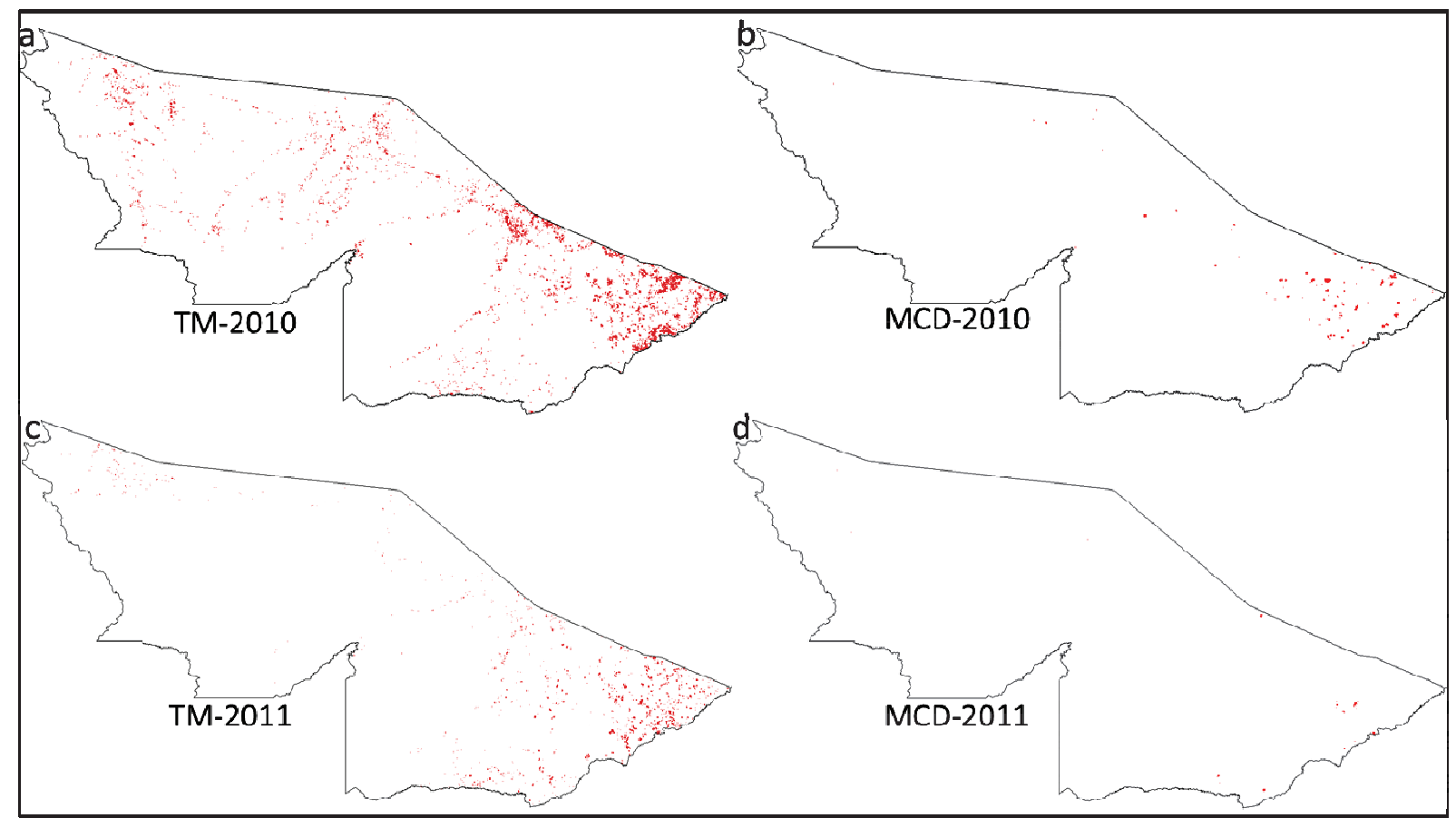

Figure 2. Acre study area: a) Mapped burned areas from TM/Landsat 5 (2010); b) MCD45A1 burned area estimation (2010);

c) Mapped burned areas from TM/Landsat 5 (2011); d) MCD45A1 burned area estimation (2011).

For this paper was also realized a field work on September 28 and 30 of 2011, and the route can be visualized in Figure 1. In this field work were collected 33 points with Global Positioning System (GPS) in local areas that had burned in order to validate the mapping. From the comparison of maps made from TM Landsat-5 images and the points collected in the field, it was noticed that 31 coincided with the burned areas mapped and 2 showed no correlation (93\% of accuracy). The cases of omission can be explained according to the duration of the scars of fires, when these scars are too olds, they are not identified in the TM sensor images.

\section{CONCLUSIONS}

It can be concluded that MCD45A1 product presented a low confidence in identifying the burned areas in Amazon region. The error accuracy in detecting burned areas, which causes a high omission in the same regions of the Brazilian forests, could be explained by several factors, including the interference of the optical depth of clouds and plumes, the lack data from sensors at the time of occurrence of a fire and mainly due to the spatial resolution, since the majority of fires that occur in South America are smaller than the spatial resolution of 500 meters of MODIS sensor.

Thus, most of the burned areas that occur in Brazil are not detected by the MODIS product MCD45A1. Also, the advancement of remote sensing techniques, combined with the emergence of new products and operational satellites, allows the identification and quantification of burned areas in large areas of land surface. However, the low spatial resolution of some products, such as MCD45A1 makes incompatible the detection and mapping in areas where fires behavior has a smaller area than sensors IFOV, as is the case of Amazon region.

\section{REFERENCES}

[1] Crutzen, P. J., and Andreae, M. O., Biomass burning in the tropics: impact on atmospheric chemistry and biogeochemical cycles, Science, v. 250, p. 1669-1678, 1990.

[2] Sampaio, G., Nobre, C., Costa, M. H., Satyamurty, P.; SoaresFilho, B. S.; and Cardoso, M. F., Regional climate change over eastern Amazonia caused by pasture and soybean cropland expansion, Geophysical Research Letters, v. 34, p. 1-7, 2007.

[3] Roy, D. P., Boschetti, L., Justice, C. O., and Ju, J., The collection 5 MODIS burned area product - Global evaluation by comparison with the MODIS active fire product, Remote Sensing of Environment, v. 112, p. 3690-3707, 2008.

[4] Giglio, L., Loboda, T., Roy, D. P., Quayle, B., and Justice, C. O., An active-fire based burned area mapping algorithm for the MODIS sensor, Remote Sensing of Environment, v. 113, p. 408420, 2009. 
[5] Pyne, S. J., Andrews, P. L., and Laven, R. D., Introduction to Wildland Fire, 2nd ed, Wiley, New York, 769 pp, 1996.

[6] Eva, H., and Lambin, E. F., Remote sensing of biomass burning in tropical regions: sampling issues and multi sensor approach, Remote Sensing of Environment, v. 64, p. 292-315, 1998.

[7] Boschetti, L., Brivio, P. A., Eva, H., Gallego, J., Baraldi, A., and Grégoire, J. M., A sampling method for the retrospective validation of global burned area products, IEEE Transactions on Geoscience and Remote Sensing, v. 44, p. 1765-1773, 2006. 